Descargo de responsabilidad: las opiniones expresadas en los manuscritos son responsabilidad exclusiva de los autores. No necesariamente reflejan las opiniones de la editorial ni la de sus miembros.

1 CANIRO IVERSITARIO

\title{
Error de tipo y error de prohibición
}

\section{The type error and prohibition error}

Recibido: 22/07/2021

Aceptado: 20/08/2021

\author{
Karen Vanessa Paz Martínez \\ Maestría Derecho Procesal Penal \\ Universidad de San Carlos de Guatemala \\ karenpaz@postgradocunzac.edu.gt
}

\section{Referencia}

Paz Martínez, K. V. (2021). Error de tipo y error de prohibición. Revista Académica Sociedad Del Conocimiento Cunzac, 1(1), 15-20. DOI: https://doi.org/10.46780/sociedadcunzac.v1i1.3

\section{Resumen}

El presente artículo aborda contenido en relación al tipo penal, el cual se puede definir como: La descripción abstracta de la norma, que el legislador plasma en la ley penal. Los cuales se encuentran en la parte especial del Código Penal, y que se conocen como delitos; y que son conductas antijurídicas sancionadas con una pena. El objetivo principal del presente artículo es la investigación concreta con el fin de determinar los tratamientos modernos que se le dan en la doctrina al error y establecer cuáles son aquellos que deben ser regulados por la legislación penal actual. Ello implica, el desarrollo de algunos ítems sobre la normativa vigente en Guatemala. Se desarrolla un análisis sobre el error, entendiendo que se refiere al error de tipo y error de prohibición, utilizando el método científico. Debe realizarse algunas consideraciones previas. La mayoría de las ocasiones en las que un sujeto conoce la prohibición general de la conducta, se planteará al menos eventualmente la prohibición penal. En todo caso, es innegable que el establecimiento de una distinción entre error de tipo y de prohibición desde una perspectiva sistemática reviste una gran dificultad, por lo que diversos autores analizan su postura.

\section{Palabras clave}

error, prohibición, tipo penal, ignorancia, hecho

\section{Abstract}

This article addresses content related to the criminal type, which can be defined as: The abstract description of the norm, which the legislator embodies in the criminal law. Which are found in the special part of the Penal Code, and which are known as crimes; and which are antijuridical conducts punished with a penalty. The main onjective of this artcle is concrete research in order to dermine the modern treatments that are given in the doctrine of error and establish which are those that must be regulated by current criminal legislation. This implies the development of some items on the current regulations in Guatemala. An analysis of the error is developed, understanding that it refers to the error of type and prohibition error, using the scientific method In my opinion, some preliminary considerations must be made. Most of the times in which a subject knows the general prohibition of the conduct, he will at least eventually consider the criminal prohi- 
bition.In any case, it is undeniable that the establishment of a distinction between type error and prohibition error from a systematic perspective is of great difficulty, which is why several authors analyze their position.

\section{Keywords}

error, prohibition, criminal type, ignorance, fact

\section{Introducción}

El error de tipo se analiza en la tipicidad, en esta figura existe ignorancia o error. La ignorancia supone la ausencia total de conocimiento; a lo que me refiero en un concepto más amplio. Para Francisco Muñoz Conde el "error es la falsa representación o la suposición equivocada de la realidad o simplemente la ignorancia". Con todo, doctrina y jurisprudencia se ha alcanzado un mínimo consentimiento sobre algunos de los principales problemas que en su momento plantean el error en la legislación guatemalteca.

Por lo tanto, el error de tipo excluye el dolo al haber desconocimiento sobre la ilicitud del hecho sobre que lo que se ataca en un bien jurídico protegido. En todo caso, es innegable que el establecimiento de una distinción entre error de tipo y de prohibición desde una perspectiva sistemática reviste una gran dificultad, por lo que diversos autores abordan como último recurso a la afirmación de que la calificación del error debe atender al sentido del concreto tipo penal de la parte especial.

Por lo tanto, todo error sobre un elemento del tipo penal necesariamente beneficiará al sujeto, ya sea eximiéndolo de responsabilidad, o enjuiciando su comportamiento dentro de un marco incriminatorio culposo. Algunos autores razonan (Cuello Calón, Eugenio) que las leyes penales castigan actos íntimamente inmorales, actos cuya criminalidad comprenden a todos, pues todos poseen el discreción para distinguir entre lo bueno y lo malo. Sin embargo, a pesar de estos testimonios y con el pensamiento de que todo el mundo conoce las leyes no es más que un mito que no responde a la realidad de las cosas.

Actualmente el error se clasifica en dos clases: error de tipo (error de hecho) y error de prohibición (error de derecho). Error de tipo: El autor Rony Eulalio López Contreras, nos da un concepto sobre el error de tipo, este se da "cuando existe un sujeto activo que ejerce una acción voluntaria, sin conocer que con su actuar está produciendo un resultado dañoso, que pone en peligro o lesiona un bien jurídico protegido".

Como casos concretos se puede mencionar, el caso figurado de que Carlos quiere matar a Juan, pero solo consigue herirle. Delito: consiste en que el delito cometido sea distinto del que el sujeto se había propuesto. Otro caso sería Mateo quiere matar el perro del vecino, dispara contra él, pero no lo alcanza y en cambio hiere a una persona. Estos casos concretos concluyen que en el error de tipo hay un desconocimiento total sobre las personas o las cosas en que se ejecuta la acción, dando lugar a cometer un delito culposo. 


\section{Materiales y métodos}

Para la redacción del presente artículo, se realizó la lectura y análisis de distintos libros en relación al error de tipo y de prohibición. Consultando además doctrina, legislación y jurisprudencia vigente guatemalteca.

\section{error de tipo y error de prohibición}

Dentro de las teorías que tratan de explicar el error, se concluye que la teoría finalista, es la que más ajusta a la realidad, debido a la idiosincrasia del delincuente y al proceso que ha venido dando en la sociedad, porque se castiga al delincuente por el acto final, no se investiga la causa que lo motivó a cometer el acto antijurídico.

En cuanto al error de prohibición este se produce cuando el sujeto, conociendo todos los supuestos positivos y negativos de la prohibición, que llevarían al hombre ideal a reconocer tal prohibición, sin embargo, por circunstancias particulares suyas, desconoce tal prohibición.

Desde el ámbito del derecho penal económico autores como Bajo Fernández proponían la siguiente regla interpretativa: el error de prohibición es invencible cuando se desconoce la norma jurídica y el conocimiento de la antijuridicidad (conocimiento de la prohibición jurídica) no puede derivarse de las reglas éticos sociales que rigen el comportamiento en comunidad. Se considera que el problema principal se encuentra en establecer si con el conocimiento por parte del sujeto de los supuestos de la prohibición se produce o no, un efecto que al hombre le haría saber que la conducta está prohibida.

Como fundamento jurisprudencial, en Guatemala como caso concreto, la Sentencia número 1379-2012 de la Corte Suprema de Justicia / Cámara Penal, en relación a un recurso de casación por motivo de fondo interpuesto por un procesado por los delitos de caza sin licencia otorgada por la autoridad correspondiente y portación ilegal de armas de fuego de uso civil y/o deportivas. De la resolución del Tribunal de Sentencia: del Tribunal de Sentencia Penal, Narcoactividad y Delitos contra el Ambiente de Escuintla, el diecisiete de agosto de dos mil once, condenó al procesado en el grado de autor por el delito de caza sin licencia otorgada por la autoridad correspondiente, en grado de tentativa, imponiéndole la pena de tres años de prisión inconmutables y lo absolvió del delito de portación ilegal de armas de fuego de uso civil y/o deportivas. El Ministerio Público presentó recurso de apelación especial por motivo de fondo, denunciando la inobservancia del artículo 123 de la ley de armas y municiones. La Corte de Constitucionalidad, estimó que la jueza, en un error en la interpretación o en la elección de la norma, exigió una prueba pericial. En el presente caso, el recurrente alega que al no haber sido individualizada el arma que portaba, no debió de habérsele condenado a una pena tan grave (10 años de prisión). Ello es la naturaleza del error de tipo, en este caso el cazador porta una escopeta y el cual goza de licencia a nombre del propietario que lo acompaña, el elemento determinante es que el propietario contaba con la licencia de portación de arma de fuego, el recurso de Casación lo declaran procedente y absuelve. 
Habrá error de tipo si el sujeto obra sin saber lo que está haciendo, en este caso se pone de manifiesto hasta qué punto una distinción precisa entre elementos descriptivos y normativos es, en sí misma, la problemática y que ni siquiera los estudiosos del derecho pueden decir que conocen toda la ley, menos aún el ciudadano que no conoce las leyes. En Guatemala la ignorancia de la ley se encuentra regulada en el artículo 3 de la ley del Organismo Judicial el cual establece: "Primacía de la ley. Contra la observancia de la ley no puede alegarse ignorarse, desuso, costumbre o practica en contrario".

La legislación penal vigente, en lo que respecta al problema del error, no se ajusta a las necesidades de los hechos jurídicos que se producen, además de las corrientes dogmáticas modernas. Para regular en forma técnica el error penal en el Código Penal guatemalteco, es necesario incluir en su normativa el error de prohibición.

Para el autor José Leandro Reaño considera que existe una amplia discusión entre el error de tipo y error de prohibición, pero se concentra más al fijar su mirada en el objeto del error.

\section{Discusión}

Dentro de los principales hallazgos del presente artículo, existe un aspecto fundamental positivo, y es el haber introducido la terminología error de tipo / error de prohibición, reemplazando la tradicional distinción entre error de hecho (error facti) y de derecho (error iuris). Así como el error de tipo no es un problema de culpabilidad o de responsabilidad penal, sino de tipicidad. Tomando en cuenta la actual y vigente normativa guatemalteca, de la que es necesario que se regulen dichos errores.

\section{Conclusión}

Pero en sí, ¿es el error de tipo, un problema de culpabilidad o de responsabilidad penal? el error de tipo no es un problema de culpabilidad o de responsabilidad penal, sino de tipicidad. Es el error del actor sobre las circunstancias ciertas o reales, es decir, existe una diferencia entre la concepción del actor y la realidad. Como causa de inculpabilidad el error, en la legislación guatemalteca, está regulado de forma antigua porque en la parte general del Código Penal específicamente en los artículos: 25 inciso 3, lo regula como causa de inculpabilidad. El artículo 26 numeral 9, lo regula como ignorancia; como una circunstancia atenuante, se entiende que se está refiriendo al error de derecho.

Ambos errores deberían estar regulados como causas de inculpabilidad y establecer la diferencia entre uno y otro error. Porque al no estar regulado apropiadamente y en forma clara, no existe forma de probarlo, y ello hace que el mismo sea una norma vigente, pero no positiva.

Es necesario en este caso que la autoridad competente regule en forma clara, precisa y concreta la figura del error y así hacer constar la diferencia entre error de tipo y error de prohibición, dentro de la ley penal vigente. Se da a conocer que en Latinoamérica comienza apenas 
a mostrarse el interés por la misma, sin embargo, existen vinculados penalistas seguidores de sus postulados. En Guatemala, el Código Penal, casi no recibió su influencia, y el Decreto Ley 17-73, del Congreso de la República se puede considerar como se dijo y se continúa aclarando una ley abiertamente causalista.

\section{Referencias}

Bajo Fernández, Miguel, El error de prohibición en el Derecho Penal Económico, en: Derecho de sociedades, Libro Homenaje a Fernando Sánchez Calero, vol. 5, 2002, 5489.

Cuello Calón, Eugenio. Derecho penal, parte general, Segunda edición aumentada y adaptada al nuevo Código Penal. Barcelona 1929. Librería Bosch. p. 460.

José Leandro Reaño Peschiera. El error de tipo en el Código Penal Peruano.

López Contreras, Dr. Rony Eulalio. Curso de Derecho Penal, Parte General. Editorial MR EDICIONES Pág. 130.

Muñoz Conde, Francisco y García Arán, Mercedes. «Manual de Derecho Penal - Parte General>>, Tirant lo blanch, Valencia, 1993, p.252.

Sentencia número 1379-2012 de Corte Suprema de Justicia.

\section{Sobre la autora}

Karen Vanessa Paz Martínez, es Licenciada en Ciencias Jurídicas y Sociales, Abogada y Notaria, propietaria de Bufete Jurídico Paz Martínez, actualmente estudiante de la Maestría de Derecho Procesal Penal del Centro Universitario de Zacapa, Universidad de San Carlos de Guatemala.

\section{Financiamiento de la investigación}

Con recursos propios de los investigadores

\section{Declaración de intereses}

Declaran no tener ningún conflicto de intereses, que puedan haber influido en los resultados obtenidos o las interpretaciones propuestas.

\section{Declaración de consentimiento informado}

El estudio se realizó respetando el Código de ética y buenas prácticas editoriales de publicación. 


\section{Derechos de uso}

Copyright@ 2021 por Karen Vanessa Paz Martínez

Este texto está protegido por una licencia Creative Commons 4.0

Este texto está protegido por la Licencia Creative Commons Atribución 4.0 Internacional.

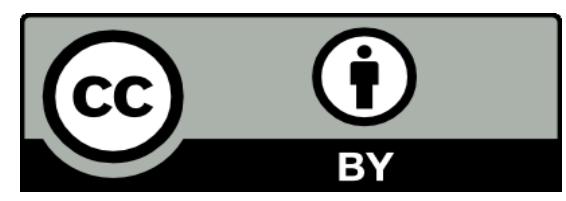

Este texto está protegido por una licencia

Creative Commons 4.0.

Es libre para compartir, copiar y redistribuir el material en cualquier medio o formato y adaptar el documento, remezclar, transformar y crear a partir del material para cualquier propósito, incluso comercialmente, siempre que cumpla la condición de atribución: debe reconocer el crédito de una obra de manera adecuada, proporcionar un enlace a la licencia, e indicar si se han realizado cambios. Puede hacerlo en cualquier forma razonable, pero no de forma tal que sugiera que tiene el apoyo del licenciante o lo recibe por el uso que hace. 